\title{
ANALISIS GREEN MARKETING TOOLS TERHADAP PURCHASE BEHAVIOUR DENGAN MEDIASI PURCHASE INTENTION PADA KONSUMEN MILENIAL DI JAKARTA
}

\author{
Windy Eka Saputri \\ Program Studi Magister Manajemen Universitas Tarumanagara \\ windy.117191019@stu.untar.ac.id \\ Anas Lutfi \\ Program Studi Magister Manajemen Universitas Tarumanagara \\ Masuk : 06-12-2020, revisi : 18-12-2020, diterima untuk diterbitkan : 19-12-2020
}

\begin{abstract}
This study aims to explain green marketing tools that influence purchase intention and purchase behavior in Jakarta to purchase Ades. The instrument of this research is a questionnaire distributed to 522 millennials in Jakarta. Data collected was analyzed using SmartPLS analysis. The results of this study indicate that there is an influence of ecolabel, ecobrand, environmental advertisement on purchase intention. In addition, there is an influence on purchase intention and purchase behavior. Furthermore, the results of the study indicate that purchase intention mediates the relationship between ecobrand and environmental advertisement towards purchase behavior.
\end{abstract}

Keywords: Ecolabel, Ecobrand, Environmental Advertisement, Purchase Intention, Purchase Behaviour

Abstrak: Penelitian ini bertujuan untuk menjelaskan green marketing tools yang purchase intention dan purchase behaviour di Jakarta pada pembelian Ades. Instrumen penelitian ini berupa kuesioner yang disebarkan kepada 522 milenial di Jakarta. Data yang terkumpul dianalisis menggunakan SmartPLS. Hasil penelitian ini menunjukkan bahwa terdapat pengaruh eco-label, eco-brand, dan environment advertisement terhadap purchase intention. Selain itu terdapat pengaruh purchase intention dan purchase behaviour. Hasil penelitian menunjukkan bahwa purchase intention memediasi hubungan antara eco-brand dan environmental advertisement terhadap purchase behaviour.

Kata Kunci: Ecolabel, Ecobrand, Environmental Advertisement, Purchase Intention, Purchase Behaviour

\section{PENDAHULUAN}

Isu pemanasan global sudah diangkat menjadi isu bertaraf global yang sudah menjadi perhatian banyak pihak sejak beberapa tahun silam. Peningkatan suhu di Bumi semakin drastis yang tak lain berdampak negatif pada kehidupan makhluk hidup yang bersinggungan langsung dengan alam, termasuk manusia. Badan Meteorologi, Klimatologi, dan Geofisika (BMKG) memprediksi bahwa kenaikan suhu di tahun 2020 sebesar 0,3 derajat celcius. Perubahan suhu dikhawatirkan terjadi akibat dari dampak penggunaan bahan-bahan kimia yang tidak ramah lingkungan (non eco-friendly). Sebagian masyarakat mulai menyadari betapa pentingnya penggunaan produk-produk eco-friendly agar dampak pemanasan global yang terus-menerus digaungkan mengalami perlambatan. Menurut Durmaz dan Sevil (2011), permasalahan ekologis seperti pemanasan global, efek rumah kaca, polusi, dan perubahan iklim sejak awal 1980-an, berhubungan langsung dengan manufaktur industri dan hal inilah yang akan secara langsung mempengaruhi aktivitas manusia seiring dengan meningkatnya permasalahan ekologis tersebut. Seiring dengan berjalannya waktu, sikap konsumen yang peduli terhadap lingkungan dapat dicerminkan melalui tindakan-tindakan yang dilakukan dalam menjaga 
lingkungan (Fraj \& Martinez, 2006). Aspek-aspek peduli terhadap lingkungan akan membuat perusahaan lebih cenderung untuk menghasilkan produk yang lebih baik berdasarkan kacamata lingkungan (Rex \& Baumann, 2007). Pakar pemasaran telah menggunakan istilah green marketing secara bergantian sebagai pemasaran sosial, pemasaran ekologis, atau pemasaran lingkungan (Tan \& Lau, 2011). Perhatian masyarakat selaku konsumen terhadap isu-isu lingkungan menjadi terlihat nyata dari meningkatnya pasar yang peduli lingkungan (Laroche et al., 2001). Ada tiga alat green marketing yang dikenal sebagai sarana untuk mengkomunikasikan praktik-praktik lingkungan perusahaan, yakni meliputi eco-label, ecobrand, dan environmental advertisement (Delafrooz et al., 2014).

PT Coca-Cola Indonesia merupakan salah satu perusahaan minuman terbesar di Indonesia yang mulai meningkatkan perhatian lebih atas isu lingkungan melalui penjualan produknya, salah satunya dengan inovasi produk yang ramah lingkungan dengan cara menampilkan produk air minum dalam kemasan (AMDK) merek Ades sebagai air minum dalam kemasan yang murni, aman dan terpercaya (Ridwan et al., 2017). Botol Ades menggunakan bahan plastik yang lebih sedikit sehingga mudah diremukkan. Dengan terbentuknya volume botol kosong yang akan menjadi lebih kecil apabila diremukkan, maka akan berdampak pada penghematan ruang di tempat sampah. Selanjutnya, penggunaan plastik yang lebih sedikit ini menghasilkan jejak emisi karbon yang lebih kecil pula saat sampah tersebut diangkut. Diharapkan dengan adanya tampilan baru ini, Ades memiliki misi untuk menjadikan Indonesia lebih baik melalui tindakan sederhana untuk lingkungan. (http://cocacolaamatil.co.id).

Studi ini memfokuskan pada perilaku konsumen Milenial karena dua alasan utama, yaitu: Pertama, konsumen Milenial sendiri memiliki daya beli terbesar dari generasi manapun dan mereka bersedia untuk mengonsumsi produk-produk tersebut (Woo, 2018). Kedua, kelompok ini mampu menjadi kelompok demografis yang efektif yang menitikberatkan pada masalah etika dan lingkungan (Popovici \& Muhcina, 2015; Young \& McCoy, 2016). "Para Millenials harus mengambil peran yang dominan dalam menjaga lingkungan. Semangat inovatif yang dimiliki millenials harus bisa juga dituangkan dalam merawat lingkungan", kata Menteri Badan Usaha Milik Negara (BUMN), Rini Soemarno (Novalius, 2019). Milenial (generasi Y) yang termasuk sebagai individu yang lahir antara tahun 1982 sampai 2001. Perlu diketahui bahwa jumlah Milenial di Indonesia pada tahun 2018 mencapai hingga angka 33,75\% (Budiarti et al., 2018).

\section{Tujuan Penelitian}

1. Untuk menguji secara empiris pengaruh eco-label terhadap purchase intention milenial di Jakarta.

2. Untuk menguji secara empiris pengaruh eco-brand terhadap purchase intention milenial di Jakarta.

3. Untuk menguji secara empiris pengaruh environmental advertisement terhadap purchase intention milenial di Jakarta.

4. Untuk menguji secara empiris pengaruh purchase intention terhadap purchase behaviour milenial di Jakarta.

\section{TINJAUAN PUSTAKA}

\section{Green Marketing}

Green marketing didefinisikan sebagai sarana mempromosikan produk dengan cara-cara yang diharapkan dapat meminimalisir dampak negatif terhadap lingkungan selama proses pengembangan produk atau layanan (Aggrawal, 2010). Green marketing juga mengacu pada organisasi yang berupaya untuk mempromosikan, menentukan harga, dan mendistribusikan produk atas dasar konsep peduli lingkungan (Sarkar, 2012). Dimensi green marketing tools terbagi menjadi tiga, yakni eco-label, eco-brand dan environmental advertisement, yang digunakan sebagai variabel independen untuk penelitian ini. Studi yang telah dilakukan 
sebelumnya lebih kepada menyoroti peranan penting yang dimainkan oleh tiga dimensi green marketing tools dalam memengaruhi green purchase behaviour (Delafrooz et al., 2014; Delmas \& Pekovic, 2013).

\section{Eco-label}

Eco-label adalah label yang mengidentifikasi keseluruhan preferensi lingkungan dari produk (misalnya barang atau jasa) dalam kategori produk berdasarkan pertimbangan siklus hidup (Bozowsky \& Mizuno, 2004). Eco-label merupakan tanda atau klaim dari perusahaan bahwa mereka telah menerapkan sejumlah metode produksi atau distribusi dengan memikirkan pertimbangan dampaknya pada lingkungan (Bruce \& Laroiya, 2007). Eco-label merujuk pada penggunaan oleh pelaku usaha dalam mempromosikan produk mereka dengan identifikasi green product (D'Souza et al., 2006). Label tersebut dapat berupa sejumlah kecil kertas yang ditempelkan, hingga diagram rumit yang dimasukkan sebagai bagian dari kemasan barang. Dalam beberapa kasus, penjual mungkin menginginkan label sederhana, tetapi sejumlah proses hukum biasanya mengarahkan mereka untuk melalui serangkaian aturan dalam memberikan informasi tambahan (Kotler \& Keller, 2012).

\section{Eco-brand}

Eco-brand secara sederhana dapat diartikan sebagai nama, simbol atau desain produk yang tidak berbahaya bagi lingkungan. Dengan memanfaatkan eco-brand sebenarnya pemasar dapat membantu konsumen untuk membedakan produk yang diinginkan dengan produk lainnya (Rahbar \& Wahid, 2011). Eco-brand sendiri berisikan mengenai komunikasi aktif serta perbedaan suatu merek dari para pesaingnya melalui atribut eco-friendly (Rios et al., 2006).

\section{Environmental Advertisement}

Environmental advertisement didefinisikan sebagai upaya untuk berbagi informasi tentang lingkungan bisnis (Ahmad et al., 2010). Environmental advertisement merupakan iklan yangbertujuan untuk mempromosikan manfaat sosial, ekonomi, dan lingkungan dari produk untuk membentuk nilai dan perilaku konsumen yang bertanggung jawab terhadap lingkungan (Chekima et al., 2016). Environmental advertisement berkaitan dengan segala permintaan yang mencakup pesan ekologis, kelestarian lingkungan, atau eco-friendly yang menargetkan kebutuhan dan keinginan para stakeholder yang peduli lingkungan (Leonidou et al., 2011).

\section{Purchase Intention}

Intensi pembelian atau purchase intention adalah jenis pengambilan keputusan dengan cara mempelajari alasan konsumen untuk membeli atau tidaknya brand (Shah et al., 2012). Keputusan pembelian yang dilakukan konsumen adalah proses yang kompleks berkaitan dengan perilaku, persepsi dan sikap konsumen. Purchase intention adalah kecenderungan untuk membeli sebuah brand yang secara umum menyesuaikan dan mempertimbangkan antara motif pembelian dengan atribut atau karakteristik brand tersebut (Belch \& Belch, 2011).

\section{Purchase Behaviour}

Menurut Kotler dan Ketler (2012), perilaku pembelian atau purchase behaviour adalah bagaimana seorang atau sekelempok individu, serta organisasi memilih, membeli, menggunakan ide, produk, pengalaman, serta bagaimana membuang produk. Purchase behaviour merupakan bagian dari perilaku manusia dengan mempelajari dan memahami purchase behaviour pemasar dapat memprediksi atau memperkirakan bagaimana pelanggan akan berperilaku di masa mendatang ketika pelanggan akan mengambil keputusan pembelian. (Kotler \& Armstrong, 2008).

\section{METODOLOGI PENELITIAN \\ Populasi dan Sampel}

Sekaran dan Bougie (2013, p. 236) menyatakan bahwa "The population refers to the entire group of people, events, or things of interest that the researcher wishes to investigate." Berdasarkan pernyataan berikut dapat diterjemahkan bahwa populasi mengacu pada seluruh kelompok orang, peristiwa, maupun hal-hal menarik yang ingin diselidiki oleh peneliti. 
Penelitian ini menggunakan populasi Milenials yang berjumlah 3.692.122 orang berdasarkan Badan Pusat Statistik (BPS) di DKI Jakarta.

Penelitian ini menggunakan non probability sampling yang merupakan pengambilan sampel di mana elemen-elemen dalam populasi tidak memiliki kesempatan yang diketahui atau ditentukan sebelumnya untuk dipilih sebagai subjek sampel (Sekaran \& Bougie, 2013, p. 394). Penelitian ini memilih Milenials di Jakarta Barat sebagai subjek penelitian. Milenials yang akan menjadi responden untuk penelitian akan diminta untuk menjawab kuesioner yang menggunakan acuan skala likert. Penentuan jumlah sampel sebagai data yang dapat dianalisis dalam penelitian kali ini, peniliti menggunakan Rumus Slovin berikut:

$$
\mathrm{n}=N /\left(1+\left(N \times \mathrm{x} \mathrm{e}^{2}\right)\right.
$$

n: Jumlah Sampel; N: Populasi; e: Batas Toleransi kesalahan $\mathrm{n}=3.692 .122 /\left(1+\left(3.692 .122 \times 0.05^{2}\right)\right)=399.9567 \approx 400$ responden

Berdasarkan hasil perhitungan tersebut diatas, maka dapat disimpulkan bahwa penilitian ini minimal memiliki 400 responden agar penelitian dianggap memiliki informasi valid dan representatif. Maka dari itu, penelitian ini akan diambil sampel sebanyak 522 responden.

\section{Kerangka Penelitian}

\section{Gambar 1}

\section{Kerangka Pemikiran}

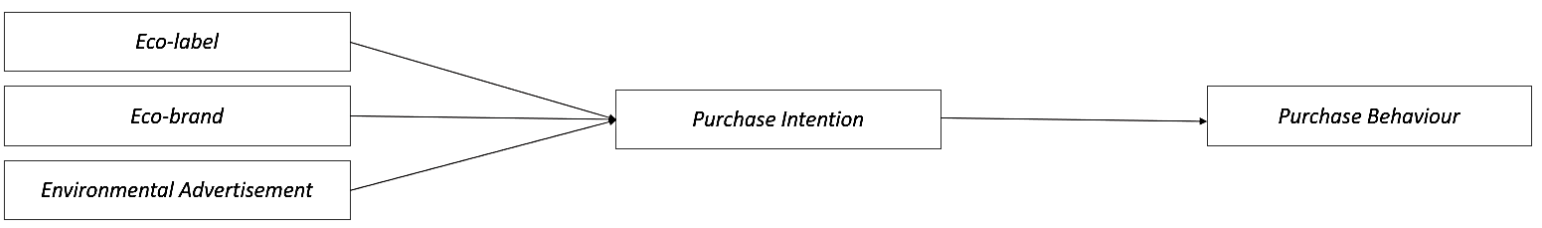

\section{HASIL DAN KESIMPULAN \\ Hasil Penelitian}

Berdasarkan analisis data dengan menggunakan evaluasi inner model terdapat satu hipotesis yang ditolak dan tiga hipotesis yang diterima. Tidak semua green marketing tools akan sesuai untuk segala perusahaan mengingat banyaknya perbedaan karakterisitik dari tiaptiap perusahaan. Eco-label menjadi satu-satunya hipotesis yang tidak diterima, masyarakat mungkin membutuhkan aksi nyata dari perusahaan. Pada dasarnya hanya sekelompok konsumen yang mampu dan bersedia untuk mencoba dan/atau membeli produk, layanan, atau menerima ide baru tanpa mengetahui terlebihi dahulu atau tanpa mendapatkan referensi dari orang lain sebelumnya. Kebanyakan orang membutuhkan semacam "bukti sosial" (Cialdini, 2001) sebelum memutuskan suatu pilihan dalam rangka pengadopsian sesuatu yang baru.

\section{Tabel 1}

\section{Hasil Uji Hipotesis}

\begin{tabular}{|c|c|c|c|c|c|}
\hline Hypothesis Relationship & Path Coef. & t Statistics & $p$-Values & Decision \\
\hline Eco-label $\rightarrow$ Purchase Intention & $\mathrm{H} 1$ & 0.047 & 0.89 & 0.374 & Not Supported \\
\hline Eco-brand $\rightarrow$ Purchase Intention & $\mathrm{H} 2$ & 0.262 & 4.128 & 0.000 & Supported \\
\hline $\begin{array}{c}\text { Environmental Advertisement } \rightarrow \text { Purchase } \\
\text { Intention }\end{array}$ & $\mathrm{H} 3$ & 0.392 & 7.734 & 0.000 & Supported \\
\hline Purchase Intention $\rightarrow$ Purchase Behaviour & $\mathrm{H} 4$ & 0.629 & 19.443 & 0.000 & Supported \\
\hline
\end{tabular}

Konsumen lebih cenderung menilai citra perusahaan melalui eco-brand. Apabila perusahaan ingin mencapai penjualan secara optimal, ada baiknya perusaahan perlu menerapkan eco-brand sebagai salah satu sarana membangun kepercayaan konsumen yang kuat. Ditambah lagi, perusahaan juga harus mampu memotivasi sikap positif konsumen terhadap eco-brand dalam memengaruhi purchase intention. Selain itu, penunjang eco-brand adalah environmental advertisement sehingga memperjelas dan memberi pemahaman tentang perusahaan yang memiliki keperdulian lingkungan yang berdampak pada purchase intention dan purchase behaviour. Environmental advertisement juga membantu membangun nilai-nilai 
positif yang kemudian mampu membuat konsumen mencapai tahap pembelian produk yang eco-friendly serta meningkatkan pengetahuan tentang produk ramah lingkungan itu sendiri. Environmental advertisement juga berguna dalam hal penanaman motivasi untuk calon pembelinya

Hasil uji hipotesis telah menunjukkan adanya korelasi yang kuat antara dua konstruk dari purchase intention dan purchase behaviour. Menurut Ling et al. (2010), purchase intention dapat diklasifikasikan ke dalam salah satu komponen perilaku kognitif konsumen mengenai individu yang hendak melakukan pembelian atas suatu merek tertentu. Pendapat ini juga seiringan dengan Teng dan Laroche (2007) yang menyebutkan bahwa purchase intention merupakan salah satu penilaian terhadap individu yang hendak membeli dan menggunakan merek tertentu.

\section{DAFTAR PUSTAKA}

Aggrawal, A. (2010). Factors affecting green marketing in India: A study of metro consumers. Padmashree Dr. D. Y. Patil University.

Ahmad, H., Shah, I. A., \& Ahmad, K. (2010). Factors in environmental advertising influencing consumer's purchase intention. European Journal of Scientific Research, 48(2), 217-226.

Belch, G., \& Belch, M. (2011). Advertising and promotion: An integrated marketing communications perspective (6th ed.). McGraw-Hill.

Bozowsky, E., \& Mizuno, H. (2004). Introduction to ecolabelling. Global Ecolabelling Network (GEN) Information Paper.

Bruce, C., \& Laroiya, A. (2007). The production of eco-labels. Environmental and Resource Economics, 36(3), 275-293. https://doi.org/10.1007/s10640-006-9028-9

Budiarti, I., Susianto, Y., P, W. P. A., Ayuni, S., Reagan, H. A., Larasaty, P., Setiyawati, N., Pratiwi, A. I., \& Saputri, V. G. (2018). Statistik gender tematik: Profil generasi milenial Indonesia (Badan Pusat Statistik (ed.)). Kementerian Pemberdayaan Perempuan dan Perlindungan Anak.

Chekima, B., Chekima, S., Syed Khalid Wafa, S. A. W., Igaua, O. A., \& Sondoh, S. L. (2016). Sustainable consumption: The effects of knowledge, cultural values, environmental advertising, and demographics. International Journal of Sustainable Development and World Ecology, 23(2), 210-220. https://doi.org/10.1080/13504509.2015.1114043

Cialdini, R. B. (2001). Influence: Science and practice. Pearson Education, Inc.

D'Souza, C., Taghian, M., \& Lamb, P. (2006). An empirical study on the influence of environmental labels on consumers. Corporate Communications, 11(2), 162-173. https://doi.org/10.1108/13563280610661697

Delafrooz, N., Taleghani, M., \& Nouri, B. (2014). Effect of green marketing on consumer purchase behavior. QScience Connect, 2014(5), 9. https://doi.org/10.5339/connect.2014.5

Delmas, M. A., \& Pekovic, S. (2013). Environmental standards and labor productivity: Understanding the mechanisms that sustain sustainability. Journal of Organizational Behavior, 34(2), 230-252. https://doi.org/10.1002/job.1827

Durmaz, Y., \& Sevil, Z. N. (2011). A theoretical approach to concept of green marketing. Interdisciplinary Journal of Contemporary Research in Business, 3(2), 1808-1814.

Fraj, E., \& Martinez, E. (2006). Influence of personality on ecological consumer behaviour. Journal of Consumer Behaviour, 5(3), 167-181. https://doi.org/10.1002/cb.169

Kotler, P., \& Armstrong, G. (2008). Prinsip-prinsip pemasaran (12th ed.). Erlangga.

Kotler, P., \& Keller, K. L. (2012). Manajemen pemasaran (12th ed.). Erlangga.

Laroche, M., Bergeron, J., \& Barbaro-Forleo, G. (2001). Targeting consumers who are willing to pay more for environmentally friendly products. Journal of Consumer 
Marketing, 18(6), 503-520. https://doi.org/10.1108/EUM0000000006155

Leonidou, L. C., Leonidou, C. N., Palihawadana, D., \& Hultman, M. (2011). Evaluating the green advertising practices of international firms: A trend analysis. Studies in Economics and Finance, 28(1), 6-33. https://doi.org/10.1108/02651331111107080

Ling, K. C., Chai, L. T., \& Piew, T. H. (2010). The effects of shopping orientations, online trust and prior online purchase experience toward customers' online purchase intention. International Business Research, 3(3), 63. https://doi.org/10.5539/ibr.v3n3p63

Novalius, F. (2019). Menteri Rini: Milenial harus menjaga dan merawat lingkungan. Okefinance. https://economy.okezone.com/read/2019/01/31/320/2012048/menteri-rinimilenial-harus-menjaga-dan-merawat-lingkungan

Popovici, V., \& Muhcina, S. (2015). An overview of millennials' coming of age. The emergence of generation $\mathrm{Y}$ and its underlying and consequential socio-economic aspects. Ovidius University Annals, Series Economic Sciences, 15(1), 341-346. https://stec.univ-ovidius.ro/html/anale/RO/2015/ANALE vol 15_issue_1.pdf

Rahbar, E., \& Wahid, N. A. (2011). Investigation of green marketing tools' effect on consumers' purchase behavior. Business Strategy Series, 12(2), 73-83. https://doi.org/10.1108/17515631111114877

Rex, E., \& Baumann, H. (2007). Beyond ecolabels: What green marketing can learn from conventional marketing. Journal of Cleaner Production, 15(6), 567-576. https://doi.org/10.1016/j.jclepro.2006.05.013

Ridwan, M., Fauzi, A., \& Bafadhal, A. S. (2017). Pengaruh green product, green advertising dan green brand terhadap keputusan pembelian (Survei pada mahasiswa jurusan Ilmu Administrasi Bisnis Angkatan 2013/2014 dan 2014/2015 Fakultas Ilmu Administrasi Universitas Brawijaya konsumen air minum kemasan mer. Jurnal Administrasi Bisnis $(J A B)$.

Rios, F. J. M., Luque Martínez, T., Moreno, F. F., \& Soriano, P. C. (2006). Improving attitudes toward brands with environmental associations: An experimental approach. Journal of Consumer Marketing, 23(1), 26-33. https://doi.org/10.1108/07363760610641136

Sarkar, A. N. (2012). Green branding and eco-innovations for evolving a sustainable green marketing strategy. Asia-Pacific Journal of Management Research and Innovation, 8(1), 39-58. https://doi.org/10.1177/2319510x1200800106

Sekaran, U., \& Bougie, R. (2013). Research methods for business: A skill building approach (5th ed.). John Wiley \& Sons.

Shah, S. S. H., Aziz, J., Jaffari, A. R., Waris, S., Ejaz, W., Fatima, M., \& Sherazi, S. K. (2012). The impact of brands on consumer purchase intentions. Asian Journal of Business Management, 4(2), 105-110. https://maxwellsci.com/print/ajbm/v4-105110.pdf

Tan, B. C., \& Lau, T. C. (2011). Green purchase behavior: Examining the influence of green environmental attitude, perceived consumer effectiveness and specific green purchase attitude. Australian Journal of Basic and Applied Sciences, 5(8), 559-567. http://ajbasweb.com/old/ajbas/2011/August-2011/559-567.pdf

Teng, L., \& Laroche, M. (2007). Building and testing models of consumer purchase intention in competitive and multicultural environments. Journal of Business Research, 60(3), 260-268. https://doi.org/10.1016/j.jbusres.2006.09.028

Woo, A. (2018). Understanding the research on millenial shopping behaviors. Forbes.Com. https://www.forbes.com/sites/forbesagencycouncil/2018/06/04/understanding-theresearch-on-millennial-shopping-behaviors/?sh=456eb31c5f7a

Young, M. E., \& McCoy, A. W. (2016). Millennials and chocolate product ethics: Saying one thing and doing another. Food Quality and Preference, 49, 42-53.

https://doi.org/10.1016/j.foodqual.2015.11.014 